\title{
Thermal Stability and Compatibility of Surfactants in Presence of Formation Water Salinity under Reservoir Conditions
}

\author{
Muhammad Khan Memon'ia, Ubedullah Ansari' ${ }^{1 b}$, Habib U Zaman Memon ${ }^{1 \mathrm{c}}$ \\ RECEIVED ON 04.10.2018, ACCEPTED ON 26.07.2019
}

\begin{abstract}
In the surfactant alternating gas injection, the injected surfactant slug is remained several days under reservoir temperature and salinity conditions. As reservoir temperature is always greater than surface temperature. Therefore, thermal stability of selected surfactants use in the oil industry is almost important for achieving their long-term efficiency. The study deals with the screening of individual and blended surfactants for the applications of enhanced oil recovery that control the gas mobility during the surfactant alternating gas injection. The objective is to check the surfactant compatibility in the presence of formation water under reservoir temperature of $90^{\circ} \mathrm{C}$ and $120^{\circ} \mathrm{C}$. The effects of temperature and salinity on used surfactant solutions were investigated. Anionic surfactant Alpha Olefin Sulfonate (AOS $\mathrm{C}_{14-16)}$ and Internal Olefin Sulfonate

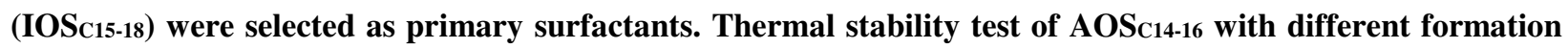
water salinity was tested at $90^{\circ} \mathrm{C}$ and $120^{\circ} \mathrm{C}$. Experimental result shows that, no precipitation was observed by surfactant $\mathrm{AOS}_{\mathrm{C} 14-16}$ when tested with different salinity at $90^{\circ} \mathrm{C}$ and $120^{\circ} \mathrm{C}$. Addition of amphoteric surfactant Lauramidopropylamide Oxide (LMDO) with AOS $_{\text {C14-16 }}$ improves the stability in the high percentage of salinity at same temperature, whereas, the surfactant blend of IOS $_{\text {C15-18 and Alcohol Aloxy Sulphate (AAS) was resulted }}$ unstable. The solubility and chemical stability at high temperature and high salinity condition is improved by

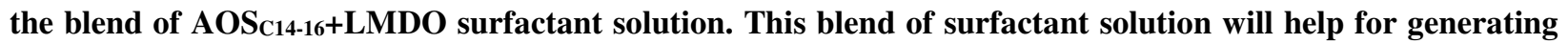
stable foam for gas mobility control in the methods of chemical Enhanced Oil Recovery (EOR).
\end{abstract}

Keywords: Divalent Ions, Foam, Surfactant, Salinity, Surfactant Alternating Gas, Thermal Stability.

\section{INTRODUCTION}

After primary and secondary oil recovery methods, about one third of the Original Oil in Place (OOIP) are remained in the pore channels of existing reservoirs due to the decline in pressure. This remained oil can be displaced from the pore channels towards the producing well by the techniques of EOR [1-2]. Thermal Stability is critical at the surface and in the reservoir conditions because surfactants are sensitive at temperature and salinity. Each reservoir has its own temperature and salinity range therefore; selection of foam forming surfactants must be stable in reservoir conditions [3]. Wettability is the most important factor in the secondary oil recovery process. Wettability alteration of reservoir rock with surfactant resulted improve the flow and fluid distribution in a pore channels of reservoir. The presence of brine water in the pore channels of the reservoir and its properties can influence the wettability and irreducible water saturation that affect the function of relative permeability. Formation water (brine water) is treated as a separate phase when used in the equations of reservoir fluid flow. The water alternating gas

\footnotetext{
${ }^{1}$ Institute of Petroleum and Natural Gas Engineering, Mehran University of Engineering and Technology, Jamshoro, Pakistan. Email: a muhammad.khan@ faculty.muet.edu.pk (Corresponding Author),

bubedullah.ansari@faculty.muet.edu.pk, chabib.memon@faculty.muet.edu.pk

This is an open access article published by Mehran University of Engineering and Technology, Jamshoro, under CC BY 4.0 International License.
} 
injection process suffers by gravity override and fingering problems in the heterogeneous oil produced reservoirs. The oil recovery remains low during the Water alternating gas injection process. The solution of improving oil recovery by this process is the addition of surfactants in brine water that reduces the problems of gravity override and fingering, therefore, improving the sweep efficiency (enhancing the oil production). Anionic surfactants are mostly used in the oil industry due to its low adsorption on rock, good foamability, biodegradability and stability in the presence of salinity and crude oil. Anionic surfactant Alpha Olefin Sulfonate is generally preferred due to its wetting characteristics (because of modification in the water-wet system) and good foaming properties in crude oil. Further, this type of surfactant provides extra ordinary detergency and biodegradability [4]. Non-ionic surfactants precipitate above the cloud point temperature because of its hydrogen bonding with water becomes weaker and their temperature reduces with salinity [5-7]. To overcome the problems of solubility and chemical stability anionic surfactants are used mostly at high temperature.

\subsection{Temperature Effect}

The most of surfactant solution have cloud point temperature (the temperature above which an aqueous solution of surfactant becomes cloud) beyond which the solution becomes cloudy. The cloudy surfactant solution due to the temperature limit is not used further for any parameter measurement. The anionic surfactants have Kraft point temperature (minimum temperature at which surfactants forms micelles). If the temperature is lower that the Kraft point temperature, surfactant solution becomes ineffective and drops out of the aqueous solution [8]. The cloud point temperature range $30-160^{\circ} \mathrm{C}$ depending upon the structure of surfactant. However, the temperature plays a minor role for a blended surfactant system due to their synergism [9]. The temperature above $120^{\circ} \mathrm{C}$ results in either degradation or precipitation of surfactants. The precipitation of surfactant in the brine water is unfavorable in the application of EOR [10].

\subsection{Salinity Effect}

Surfactant cannot work better in the high salinity environment. Therefore, the selection of particular surfactant should have an optimum salinity level at which oil and water can be equally solubilized into a micro emulsion [11]. Also the capacity of water solubilization for a particular micro emulsion is narrowly related to the partition of co-surfactants between water, oil and interfaces, chain length and nature of crude oil [11-13]. However, the design of appropriate surfactants at high temperatures (from 70$120^{\circ} \mathrm{C}$ ) and high salinity condition is challenging due to limitations in solubility and chemical stability [1415]. In this study, the individual and blended surfactant solution prepared in the different brine water salinity and tested at 90 and $120^{\circ} \mathrm{C}$ to prevent the surfactant precipitation.

\section{MATERIALS}

Anionic surfactant $\mathrm{AOS}_{\mathrm{C} 14-16}, \mathrm{IOS}_{\mathrm{C} 15-18}, \mathrm{AAS}$ and amphoteric surfactant LMDO are used in this study. Salts (sodium chloride, magnesium chloride and calcium chloride) are used for preparing synthetic brine water with different salinity. Tables 1-2 show the ionic composition of synthetic (laboratory prepared) brine water.

\begin{tabular}{|c|c|c|c|}
\hline \multicolumn{5}{|c|}{ Table 1: Composition of Synthetic Brine Water for } \\
Surfactant AOS \\
C14-16 \\
\hline Salt (ppm) & $\begin{array}{c}\text { Brine Water } \\
\text { (A) }\end{array}$ & $\begin{array}{c}\text { Brine Water } \\
\text { (B) }\end{array}$ & $\begin{array}{c}\text { Brine Water } \\
\text { (C) }\end{array}$ \\
\hline Sodium & 27521.367 & 19658.119 & 11794.87 \\
\hline Chloride & 49400.76 & 39532.17 & 30071.648 \\
\hline Calcium & 2522.52 & 3603.60 & 4324.324 \\
\hline Magnesium & 836.69 & 956.22 & 1434.33 \\
\hline
\end{tabular}

\section{METHODOLOGY}

The first step of experiment is related to the testing of surfactant solutions for aqueous stability. The surfactant solution was mixed with maximum brine salinity at high temperature. $10 \mathrm{ml}$ of each concentrated solution of surfactant was taken in a glass test tube, and then allowed to settle for an hour in an oven at reservoir temperature of 90 and $120^{\circ} \mathrm{C}$. The surfactant solution was considered table when no phase separation or clouds has been observed. Fig. 1(a) shows the experimental setup of thermal stability of tested samples and Fig. 1(b) shows the clear surfactant solutions (no clouds and no precipitates shown in the test tubes). 


\begin{tabular}{|c|c|c|c|c|c|}
\hline \multicolumn{7}{|c|}{ Table 2: Composition of Synthetic Brine Water for Surfactant Blends } \\
\hline Salt (ppm) & Brine Water (A) & Brine Water (B) & Brine Water (C) & Brine Water (D) & Brine Water (E) \\
\hline $\mathrm{Na}$ & 19658.119 & 27521.367 & 35384.615 & 47179.487 & 58974.358 \\
\hline $\mathrm{Cl}$ & 45175.037 & 57311.789 & 64504.152 & 76717.185 & 91025.641 \\
\hline $\mathrm{Ca}$ & 5405.405 & 5405.405 & 3603.603 & 1801.801 & - \\
\hline $\mathrm{Mg}$ & 1792.916 & 1792.916 & 1195.277 & 239.408 & - \\
\hline $\begin{array}{l}\text { Total brine } \\
\text { salinity (ppm) }\end{array}$ & 72031.477 & 92031.477 & 104687.647 & 125937.881 & 150000 \\
\hline
\end{tabular}

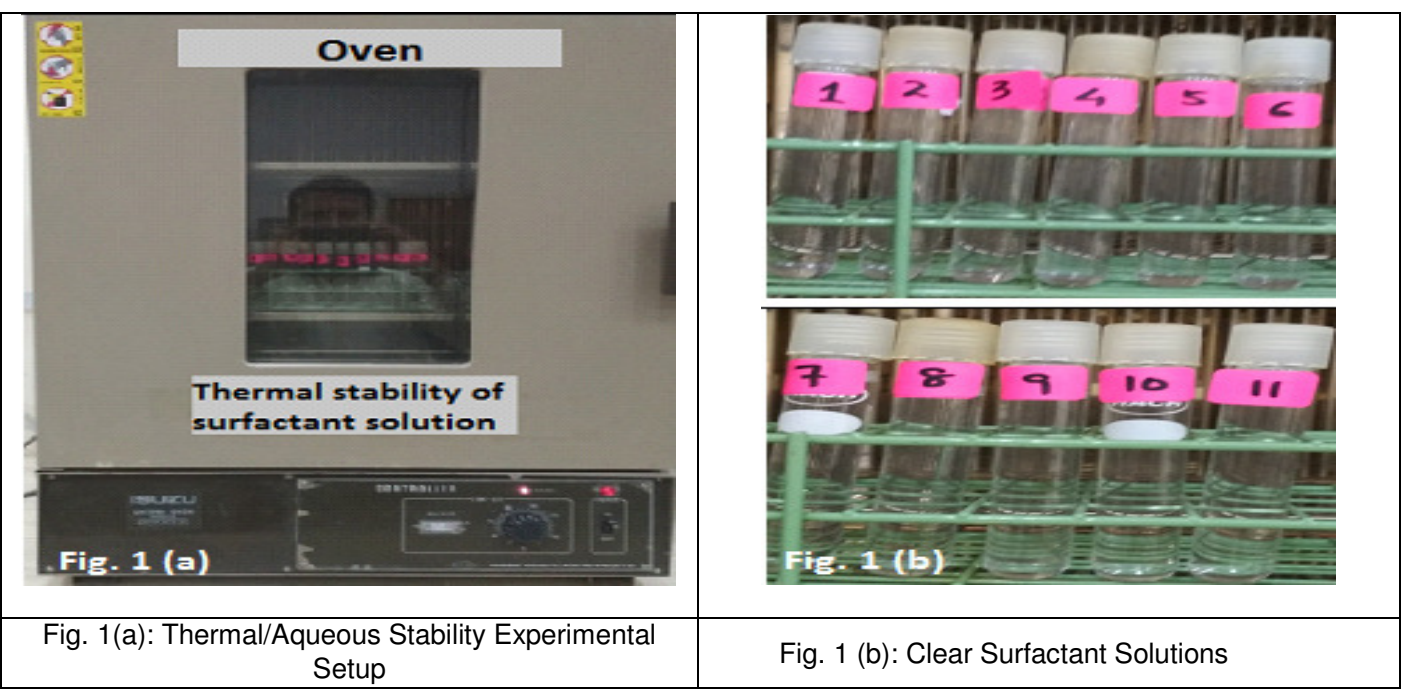

\section{RESULTS AND DISCUSSION}

Low and high concentration of $\mathrm{AOS}_{\mathrm{C} 14-16}$ was tested in the presence of different brine salinities with divalent ions. The solution was tested with Brine-A, Brine-B and Brine-C as shown in the Table 1. From the aqueous thermal stability test, $\mathrm{AOS}_{\mathrm{C} 14-16}$ was stable in maximum brine salinity of $80281.4 \mathrm{ppm}$ (Brine-A) with minimum divalent ions at temperature 90 and $120^{\circ} \mathrm{C}$ for an hour. When the percentage of divalent ions were increased to $3603.60 \mathrm{ppm}$ of $\mathrm{Ca}++$, and 956.22ppm of $\mathrm{Mg}++$ ions (Brine-B), the $\mathrm{AOS}_{\mathrm{C} 14-16}$ solution remained stable and no cloud was observed at 90 and $120^{\circ} \mathrm{C}$. Increasing the percentage of divalent ions with $\mathrm{AOS}_{\mathrm{C} 14-16}$ solution at low and high concentration led to a decrease in the percentage of monovalent ions ( $\mathrm{Na}$ ions and $\mathrm{Cl}$ ions). In Brine- $\mathrm{C}$, the percentage of divalent ions was increased as 4324.32ppm of $\mathrm{Ca}++$ ions and 1434.3ppm of $\mathrm{Mg}++$ ions resulted into decrease in monovalent ions. The $\mathrm{AOS}_{\mathrm{C} 14-16}$ was stable in the maximum divalent ions for the composition of (Brine-C) as compared to the composition of (Brine-A and Brine-B). Therefore, the stability test result shows that, the surfactant $\mathrm{AOS}_{\mathrm{C} 14}$ 16 was soluble in the total brine salinity of $80281.4 \mathrm{ppm}$ with 2522.52ppm of $\mathrm{Ca}^{++}$ions and $836.69 \mathrm{ppm}$ of $\mathrm{Mg}^{++}$ ions at $90^{\circ} \mathrm{C}$ and $120^{\circ} \mathrm{C}$. No precipitation and clouds were shown. Stability was generated due to the hydrogen bonds that formed between the head groups, i.e. when the polar head group has a hydrogen bond donor and proton acceptor [16-18].

Equal concentration of $\mathrm{AOS}_{\mathrm{C} 14-16}$ was blended with LMDO to maximize the range of divalent ions. As $\mathrm{AOS}_{\mathrm{C} 14-16}$ is limited to the salinity and LMDO is tolerant to divalent ions. The blend of surfactant solution was tested with Brine-A to Brine-E as shown in the Table 2. Low concentration of this surfactant blend solution was tested and resulted unstable in presence of high brine salinity at 90 and $120^{\circ} \mathrm{C}$, but the same blend was tested in the low brine salinity (BrineA) and shown stable at same conditions. High concentration of this blend was tested and observed stable in Brine-B-E at $90^{\circ} \mathrm{C}$ and $120^{\circ} \mathrm{C}$. This surfactant blend solution showed long term thermal stability. No clouds were shown. Table 3 shows different concentration of $\mathrm{AOS}_{\mathrm{C} 14-16}$ and blend of $\mathrm{AOS}_{\mathrm{C} 14-16}$ with LMDO surfactant in the presence of brine salinity. Low and high concentration of $\operatorname{IOS}_{\mathrm{C} 15-18}$ was 
blended with AAS. Additive AAS was used due to its excellent divalent ion tolerance. The result showed clouds in the both tested solution and this surfactant blend was considered unstable in the Brine-A-E. The instability in the both solution of this surfactant blend is due to the limited solubility in the brine water.

The percentage of brine salinity was increased due to the synergy of the $\mathrm{AOS}_{\mathrm{C} 14-16}$ and LMDO surfactant. Therefore, the blend of $\mathrm{AOS}_{\mathrm{C} 14-16}$ and LMDO surfactant solution was stable in the maximum brine salinity of $125937.881 \mathrm{ppm}$ with $1801.801 \mathrm{ppm}$ of $\mathrm{Ca}^{++}$ ions and $239.408 \mathrm{ppm}$ of $\mathrm{Mg}^{++}$ions at $90^{\circ} \mathrm{C}$ and $120^{\circ} \mathrm{C}$. Further, the same concentration of this blended surfactant was tested in presence of $150000 \mathrm{ppm}$ (Brine-E) without divalent ions. No precipitation and clouds were shown in the test tube. Formation brines with maximum divalent ions are generally considered as difficult targets. Surfactant blend solution exhibited good salt tolerance. Blend of $\mathrm{AOS}_{\mathrm{C} 14-16}$ and LMDO was shown good stability in presence of such reservoir conditions.

\section{CONCLUSIONS}

1. Individual surfactant $\mathrm{AOS}_{\mathrm{C} 14-16}$ was stable in maximum salinity of $80281 \mathrm{ppm}$ at 90 and $120^{\circ} \mathrm{C}$. No clouds or precipitation was observed.

2. Blend of surfactant solution $\mathrm{IOS}_{\mathrm{C} 15-18}+\mathrm{AAS}$ showed clouds in Brine Water-A-E.

3. Surfactant blend with low and high concentration of $\mathrm{AOS}_{\mathrm{C} 14-16}+\mathrm{LMDO}$ showed good tolerance in salt concentration and thermal stability in the aqueous phase. Interfacial tension and core flood tests are recommended to validate the performance of surfactants.

\section{KNOWLEDGMENT}

The author would like to acknowledge the Institute of Petroleum and Natural Gas Engineering, Mehran University of Engineering \& Technology Jamshoro, Sindh, Pakistan, for supporting the laboratory facility.

\section{REFERENCES}

1. Leray, S., Douarche, F., Tabary, R., Peysson, Y., Moreau, P., and Preux, C., "Multi Objective Assisted Inversion of Chemical EOR Corefloods for Improving the Predictive Capacity of Numerical Models", Journal of Petroleum Science and Engineering, Vol. 146, pp. 11011115, 2016.

2. Druetta, P., Yue, J., Tesi, P., De Persis, C., and Picchioni, F., "Numerical Modeling of a Compositional Flow for Chemical EOR and Its Stability Analysis", Applied Mathematical Modelling, Vol. 47, pp. 141-159, 2017.

3. Stevenson, P., "Foam Engineering: Fundamentals and Applications", John Wiley \& Sons Ltd, UK, 2012.

4. Chen, S., Liu, H., Zhu, Y., Li, W., Yan, X., Wang, G., and Zhang, J., "Experimental and Mathematical Modeling Investigation on the Dynamic Viscoelasticity Behavior of Free Liquid Films Prepared by Alpha Olefin Sulfonate", Journal of Molecular Liquids, Vol. 251, pp. 218228, 2018.

5. Adkins, S.S., Chen, X., Chan, I., Torino, E., Nguyen, Q.P., Sanders, A.W., and Johnston, K.P., "Morphology and Stability of $\mathrm{CO}_{2}$-in-Water Foams with Nonionic Hydrocarbon Surfactants", ACS Publications LANGMUIR, Vol. 26, No. 8, pp. 5335-5348, 2010.

\begin{tabular}{|c|c|c|c|c|c|}
\hline \multicolumn{5}{|c|}{ Table 3: Thermal Stability of Blended Surfactants at $90^{\circ} \mathrm{C} \& 120^{\circ} \mathrm{C}$ in the Brine Water of Table 2} \\
\hline $\begin{array}{c}\text { Surfactant Concentration } \\
(\mathrm{wt} \%)\end{array}$ & $\begin{array}{c}\text { Brine Water } \\
(\mathrm{A})\end{array}$ & $\begin{array}{c}\text { Brine Water } \\
(\mathrm{B})\end{array}$ & $\begin{array}{c}\text { Brine Water } \\
(\mathrm{C})\end{array}$ & $\begin{array}{c}\text { Brine Water } \\
(\mathrm{D})\end{array}$ & $\begin{array}{c}\text { Brine Water } \\
(\mathrm{E})\end{array}$ \\
\hline $0.2 \% \mathrm{AOS}_{\mathrm{C} 14-16}+0.2 \% \mathrm{LMDO}$ & \multirow{2}{*}{ Stable } & Not Stable & Not Stable & Not Stable & Not Stable \\
\cline { 4 - 7 } & Stable & Stable & Stable & Stable \\
\hline $0.6 \% \mathrm{AOS}_{\mathrm{C} 14-16}+0.6 \% \mathrm{LMDO}$ & \multirow{2}{*}{ Not Stable } & \multirow{2}{*}{ Not Stable } & Not Stable & Not Stable & Not Stable \\
\hline $0.2 \% \mathrm{IOS}_{\mathrm{C} 15-18}+0.2 \% \mathrm{AAS}$ & & &
\end{tabular}


6. Adkins, S.S., Chen, X., Chan, I., Torino, E., Nguyen, Q.P., Sanders, A.W., and Johnston, K.P., "Morphology and Stability of $\mathrm{CO}_{2}$-in-Water Foams with Nonionic Hydrocarbon Surfactants", ACS Publications LANGMUIR, Vol. 26, No. 8, pp. 5335-5348, 2010.

7. Mukherjee, P., Padhan, S.K., Dash, S., Patel, S., and Mishra, B.K., "Clouding Behaviour in Surfactant Systems", Advances in Colloid and Interface Science, Vol. 162, Nos. 1-2, pp. 59-79, 2011.

8. Chen, Y., Elhag, A.S., Cui, L., Worthen, A.J., Reddy, P.P., Noguera, J.A., and Hirasaki, G.J., " $\mathrm{CO}_{2}$-in-Water Foam at Elevated Temperature and Salinity Stabilized with a Nonionic Surfactant with a High Degree of Ethoxylation”, Industrial and Engineering Chemistry Research, Vol. 54, No. 16, pp. 4252-4263, 2015.

9. Karnanda, W., Benzagouta, M., Al-Quraishi, A., and Amro, M., "Effect of Temperature, Pressure, Salinity, and Surfactant Concentration on IFT for Surfactant Flooding Optimization", Arabian Journal of Geosciences, Vol. 6, No. 9, pp. 35353544, 2013.

10. Ye, Z., Zhang, F., Han, L., Luo, P., Yang, J., and Chen, H., "The Effect of Temperature on the Interfacial Tension Between Crude Oil and Gemini Surfactant Solution", Colloids and Surfaces A: Physicochemical and Engineering Aspects, Vol. 322, Nos. 1-3, pp. 138-141, 2008.

11. Rashidi, M., Blokhus, A.M., and Skauge, A., "Viscosity Study of Salt Tolerant Polymers", Journal of Applied Polymer Science, Vol. 117, No. 3, pp. 1551-1557, 2010.

12. Bera, A., Ojha, K., Kumar, T., and Mandal, A., "Water Solubilization Capacity, Interfacial Compositions and Thermodynamic Parameters of Anionic and Cationic Microemulsions", Colloids and Surfaces A: Physicochemical and Engineering Aspects, Vol. 404, pp. 70-77, 2012.

13. Bera, A., Ojha, K., Mandal, A., and Kumar, T., "Interfacial Tension and Phase Behavior of Surfactant-Brine-Oil System", Colloids and Surfaces A: Physicochemical and Engineering Aspects, Vol. 383, Nos. 1-3, pp. 114-119, 2011.

14. Bera, A., Kumar, T., Ojha, K., and Mandal, A., "Screening of Microemulsion Properties for
Application in Enhanced Oil Recovery", Fuel, Vol. 121, pp. 198-207, 2014.

15. Puerto, M., Miller, C.A., Hirasaki, G.J., and Barnes, J.R., "Surfactant Systems for EOR in High-Temperature, High-Salinity Environments", SPE Journal, Vol. 17, No. 1 pp. 11-19, 2012.

16. Dupas, A., Hénaut, I., Argillier, J.-F., and Aubry, T., "Mechanical Degradation Onset of Polyethylene Oxide Used as a Hydrosoluble Model Polymer for Enhanced Oil Recovery", Oil and Gas Science and Technology-Revue IFP Energies Nouvelles, France, Vol. 67, No. 6, pp. 931-940, 2012.

17. Maeda, H., Muroi, S., Ishii, M., Kakehashi, R., Kaimoto, H., Nakahara, T., and Motomura, K., "Effects of Ionization on the Critical Micelle Concentration and the Surface Excess of Dodecyldimethylamine Oxide in Salt Solutions", Journal of Colloid and Interface Science, Vol. 175, No. 2, pp. 497-505, 1995.

18. Maeda, H., "Dodecyldimethylamine Oxide Micelles: Stability, Aggregation Number and Titration Properties", Colloids and Surfaces A: Physicochemical and Engineering Aspects, Volume 109, pp. 263-271, 1996. 